\title{
Aplikasi Sistem Informasi Pelayanan Publik (SIPP) Berbasis Web Pada Kantor Urusan Agama Sungai Raya
}

\author{
Dedi Saputra ${ }^{1}$, Wahyu Hardianti Saputri ${ }^{2}$, Fajar Akbar ${ }^{3}$ \\ ${ }^{1,2}$ Universitas Bina Sarana Informatika \\ e-mail: 1dedi.dst@bsi.ac.id, ${ }^{2}$ wahyuhardiantisaputri@gmail.com \\ ${ }^{3}$ Universitas Nusa Mandiri \\ e-mail: fajar.fkb@nusamandiri.ac.id
}

\begin{abstract}
Abstrak - Kantor Urusan Agama (KUA) merupakan salah satu instansi yang harus mempunyai sistem informasi berbasis web untuk menunjang dan memberikan pelayanan yang efisien serta efektif kepada publik atau masyarakat. KUA saat ini masih menggunakan sistem manual untuk pendaftaran maupun penyimpanan berkas dan lain sebagainya seperti menggunakan lembar formulir untuk mengisi data-data yang diperlukan. Maka dari itu penulis mencoba membuat Aplikasi Sistem Informasi Pelayanan Publik (SIPP) Berbasis Web pada Kantor Urusan Agama Sungai Raya yang sampai saat ini masih belum memiliki web untuk mempermudah masyarakat mengakses informasi dengan mudah. Penulis ingin menerapkan sebuah aplikasi atau sebuah situs web yang dapat diakses oleh masyarakat. Seperti melakukan pendaftaran, masyarakat nantinya hanya perlu mengaksesnya melalui komputer yang terkoneksi dengan jaringan, melakukan registrasi, dan memilih metode pembayaran sesuai dengan yang tertera pada web. Kemudian untuk melengkapi berkas-berkas seperti lampiran surat, pass foto ataupun Kartu Tanda Penduduk, masyarakat hanya perlu memindai dan mengunggahnya pada kolom yang telah tersedia. Penulis menggunakan metode penelitian waterfall untuk merealisasikan program yang penulis buat. Hasil keseluruhan dari program ini adalah terciptanya sebuah website yang akan membuat informasi mengenai KUA lebih efisien untuk diakses oleh masyarakat. Jika sebelumnya untuk mengetahui apa saja pelayanan yang ada di KUA harus datang langsung ke Kantor Urusan Agama yang ada diwilayah tersebut, dengan adanya website ini masyarakat bisa melihat pelayanan-pelayanan yang ada melalui website.
\end{abstract}

Kata Kunci : Aplikasi, Sistem Informasi, Web

Abstract - The Office of Religious Affairs (KUA) is one of the agencies that must have a web-based information system to support and provide efficient and effective services to the public or the public. KUA currently still uses a manual system for registration and file storage and so on such as using form sheets to fill in the necessary data. Therefore, the author tried to create a Web-Based Public Service Information System (SIPP) Application at Sungai Raya Religious Affairs Office which until now still does not have a web to make it easier for people to access information easily. The author wants to implement an application or a website that can be accessed by the public. Like registering, people will only need to access it through a computer connected to the network, register, and choose a payment method as stated on the web. Then to complete files such as letter attachments, photo passes or Identity Cards, people only need to scan and upload them in the available columns. The author uses waterfall research methods to realize the program that the author created. The overall result of this program is the creation of a website that will make information about KUA more efficient to be accessed by the public. If previously to find out what services are in KUA must come directly to the Office of Religious Affairs in the region, with this website the public can see the services that exist through the website.

Keywords: Application, Information Systems, Web

\section{PENDAHULUAN}

Pelayanan menurut Kamus Besar Bahasa Indonesia (KBBI) adalah sebagai suatu usaha untuk membantu menyiapkan atau mengurus apa yang diperlukan orang lain.
Sedangkan menurut (Rahmadana et al., 2020) pelayanan adalah kegiatan yang dilakukan oleh seseorang atau sekelompok orang dengan landasan factor materi melalui sistem, prosedur atau metode tertentu dalam rangka usaha memenuhi kepentingan orang lain sesuai dengan haknya(Hadi et al., 2020). 
Pada perusahaan baik instansi-instansi maupun sebuah organisasi saat ini penerapan teknologi informasi sangat membantu, termasuk juga pada Kantor Urusan Agama. Contohnya untuk penginputan data, penyimpanan dan pengolahan data manual lainnya yang masih digunakan pada instansi tersebut dapat terbantu dengan adanya teknologi informasi berbasis web. Upaya memperbaiki sertameningkatkan kinerja pada instansi layanan masyarakat ini harus dilakukan secara terus menerus hingga dapat dilihat manfaatnya untuk masyarakat. Dengan demikian masyarakat sebagai pengguna layanan publik tersebut dapat menerima layanan sesuai kebutuhannya.

Upaya peningkatan kualitas pelayanan publik ini dapat dilakukan dengan memperbaiki manajemen dan pengelolaan pelayanan, yaitu dengan meminimalisir kesenjangan antara tingkat layanan yang disediakan oleh instansi dengan keinginan masyarakat(Dwiyanto, 2021). Untuk memperbaiki kualiatas layanan ini, Kantor Urusan Agama (KUA) harus mampu menerapkan teknik pengelolaan serta manajemen yang berorientasi pada kebutuhan masyarakat.

Penggunaan Sistem Informasi Pelayanan Publik Berbasis Web pada Kantor Urusan Agama Sungai Raya menggunakan 2 level, yaitu admin dan pemohon. Adapun dalam pembuatan sistem informasi ini, penulis menggunakan aplikasi web editor seperti: Sublime Text version 3.0, Xampp, MySQL, Bootstrap, CodeIgniter (CI) sebagai software pendukung, serta Adminer sebagai aplikasi pengelolaan database.

Penelitian terdahulu oleh (W. H. Ibrahim \& Maita, 2017), menyatakan bahwa Sistem Informasi Pelayanan Publik Berbasis Web, dimana di dalam website ini masyarakat dapat mengisi langsung form pengaduan dan melihat informasi yang berhubungan dengan Dinas Pekerjaan Umum Kabupaten Kampar.

Penelitian lain menyatakan bahwa Pelayanan adalah pendekatan yang lengkap yang menghasilkan kualitas pelayanan bagi masyarakat/ pelanggan. Pelayanan merupakan penggerak utama bagi operasional kegiatan bisnis dan ini memegang peranan yang sangat penting. Reformasi pelayanan publik menghendaki perubahan banyak hal, berawal dari paradigma, visi, misi, kebijakan/ strateginya, hingga konsep pelayanan publik yang prima dan implementasinya (H. A. Ibrahim, 2019).

Penelitian lain menyatakan Pada dasarnya setiap manusia membutuhkan pelayanan bahkan dikatakan bahwa pelayanan tidak dapat dipisahkan dengan kehidupan manusia itu sendiri seperti seorang bayi yang selalu menginginkan pelayanan dari seorang ibu. Dalam kehidupan bernegara, setiap warga negara juga membutuhkan pelayanan dari pemerintah atau birokrat sebagai pengendali kekuasaan yang dinamakan pelayanan publik (public services). Dengan kebijakan-kebijakan yang diambil dan ditelorkan oleh pemerintah mereka berharap semua keinginan warga negaranya, bukan sebaliknya warga negaralah yang melayani pemerintah selama roda pemerintahan berjalan (Sinambela, 2019).

\section{METODE PENELITIAN}

Penelitian ini menggunakan metode penelitian deskriptif karena dalam pelaksanaannya meliputi data, analisis dan interpretasi tentang arti dan data yang diperoleh. (Saputra, Irmayani, et al., 2019).

Metode pengembangan perangkat lunak ini menggunakan metode waterfall. Metode waterfall sering juga disebut model sekuensial linier (sequential linear) atau alur hidup klasik (classic life cycle)(Maulana et al., 2020). Model air terjun menyediakan pendekatan alur hidup perangkat lunak secara sekuensial atau terurut dimulai dari analsis desain, pengodean, pengujian, dan tahap pendukung (support)(Saputra, Setiaji, et al., 2019). Berikut adalah tahapan-tahapan metode waterfall menurut (Wijaya, 2020):

1. Analisis kebutuhan perangkat lunak

Penulis melakukan pengumpulan data secara intensif untuk menspesifikasikan kebutuhan perangkat lunak agar kedepannya dapat dipahami oleh user.

2. Desain

Pada pembuatan desain program perangkat lunak penulis memfokuskan pada struktur data, arsitektur perangkat lunak, representasi antarmuka dan prosedur pengodean.

3. Pembuatan kode program

Penulis mentranslasikan desain kedalam program perangkat lunak. Pengkodean pada tahap ini adalah agar program computer sesuai dengan desain yang telah dibuat desain.

4. Pengujian

Pengujian fokus pada perangkat lunak secara dari segi lojik dan fungsional dan memastikan bahwa semua bagian sudah diuji. Hal ini dilakukan untuk meminimalisir kesalahan (error) dan memastikan keluaran yang dihasilkan sesuai dengan yang diinginkan.

5. Pendukung (support) atau pemeliharaan (maintenance)

Tidak menutup kemungkinan sebuah perangkat lunak mengalami perubahan ketika sudah dikirimkan ke user. Perubahan bisa terjadi karena adanya kesalahan yang muncul dan tidak terdeteksi saat pengujian atau perangkat lunak harus beradaptasi dengan lingkungan baru. Tahap pendukung atau pemeliharaan dapat mengulangi proses pengembangan mulai dari analisis spesifikasi untuk perubahan perangkat lunak yang 
sudah ada, tapi tidak untuk membuat perangkat lunak baru.

\section{HASIL DAN PEMBAHASAN}

\section{Analisis Kebutuhan}

Aplikasi sistem mempunyai peranan penting dalam menyediakan informasi bagi manajemen. Informasi yang dapat berguna sebagai dasar pengambilan kebutuhan pada sistem yang berjalan saat ini, pelaksanaannya belum sepenuhnya dikerjakan dengan komputerisasi dan belum dapat hasil yang maksimal sehingga dalam pendaftaran pernikahan pada KUA masih kurang sempurna dan kadang terjadi kesalahan pada prosesnya(Akbar \& Setiaji, 2020)(Rahman et al., 2020).

Untuk menghindari kesalahan dan keterlambatan dalam proses pendaftaran maka dibangun sistem yang terkomputerisasi, sehingga diharapkan sistem pendaftaran pernikahan ini dapat membantu masyarakat dalam mendapatkan informasi dan juga penggunaan untuk pendaftarannya.

Adapun solusi yang saya kembangkan adalah aplikasi sistem informasi pelayanan publik KUA berbasis web ini terdiri dari beberapa fitur sistem seperti adanya halaman pengguna, beranda, tentang KUA, visi dan misi, dan pendaftaran. Halaman pendaftaran dapat diakses oleh semua pendaftar, yang terlebih dahulu mendaftar dengan mengisi data-data diri yang diperlukan untuk diproses, lalu mengunggah berkas yang sudah di scan seperti kartu keluarga, pas poto dan sebagainya. Sedangkan halaman administrator bisa digunakan oleh petugas dengan login terlebih dahulu.

\section{Kebutuhan Fungsional (Functional Requirement)}

Kebutuhan fungsional adalah kebutuhan utama yang diharapkan dari aplikasi yang terkait langsung dengan aplikasi ini. (Martias et al., 2020)(Haryani \& Saputra, 2021). Kebutuhan fungsional dari aplikasi ini adalah sebagai berikut:

\section{Administrator}

a. Login

Untuk dapat masuk ke sistem ini admin harus melakukan login terlebih dahulu dengan mengisi kolom username dan password dihalaman login agar dapat masuk ke home/halaman administrator.

b. Informasi

Pada menu ini bisa dilihat adanya data informasi KUA Sungai Raya.

c. Pemohon

Pada menu ini terdapat data pemohon yang sudah masuk.

d. Pegawai

Terdapat informasi pegawai yang login.

2. Pemohon

a. Login

Untuk dapat masuk ke sistem ini pendaftar harus melakukan login terlebih dahulu dengan mengisi kolom username dan password di halaman login.

b. Isi Formulir

Terdapat formulir online untuk pendaftaran bagi pemohon.

c. Upload Dokumen Persyaratan

Dihalaman ini terdapat persyaratan dokumen yang harus di unggah pemohon.

\section{Kebutuhan Non Fungsional (Non Functional Requirement)}

Adapun uraian kebutuhan non fungsional aplikasi sistem pelayanan publik berbasis website pada KUA Sungai Raya sebagai berikut:

1. Perangkat Keras (hardware)

Adapun perangkat keras (hardware) yang dibutuhkan dengan spesifikasi minimal adalah sebagai berikut:
a. Processor: $200 \mathrm{Ghz}$.
b. Installed memory (RAM) : 2GigaByte
c. Mouse : Touchpad
d. Harddisk : 500 GigaByte
e. Monitor : Resolution 1280 x 800 Pixel $L C D$
f. Keyboard : 86 Keys

2. Perangkat Lunak (software)

Adapun perangkat lunak (software) yang dibutuhkan dengan spesifikasi minimal adalah sebagai berikut:

a. Sistem operasi yang digunakan untuk membuat aplikasi sistem informasi pelayanan publik pada Kantor Urusan Agama Sungai Raya adalah Microsoft Windows 10.

b. Aplikasi web server yang digunakan adalah Xampp.

c. Aplikasi untuk pengelolaan database yang digunakan adalah Adminer.

d. Bahasa pemgrograman yang digunakan yaitu : HTML, JQuery, Javascript, PHPdengan menggunakan aplikasi Sublime Text 3 sebagai text editor.

e. Aplikasi web browser yang dapat digunakan adalah Google Chrome.

3. Pengguna (brainware)

Brainware merupakan alat perangkat akal sistem komputer yang dalam hal ini adalah manusia. Manusia merupakan pengoperasi, pengelola dan bahkan pengembang dari sebuah sistem komputer. Dan adapun yang menggunakan sistem informasi pelayanan publik ini adalah admin dan masyarakat.

\section{Rancangan Database Entity Relationship Diagram (ERD)}

ERD merupakan salah satu model yang digunakan untuk mendesain database dengan tujuan menggambarkan data yang berelasi pada sebuah database(Yulia \& Nuris, 2018). 


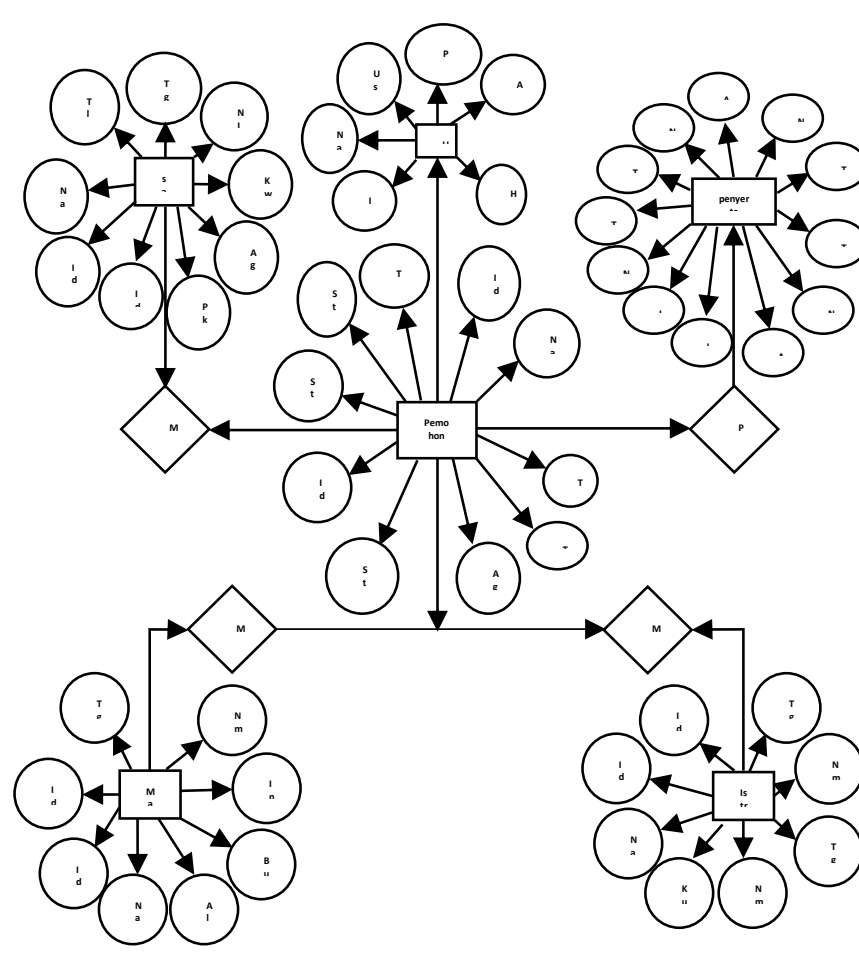

Gambar 1. Entity Relationship Diagram

\section{Logical Record Structure (LRS)}

LRS adalah referensi dari struktur record-record pada tabel-tabel yang terbentuk dari hasil relasi antar himpunan entitas.(Hasan, 2017)

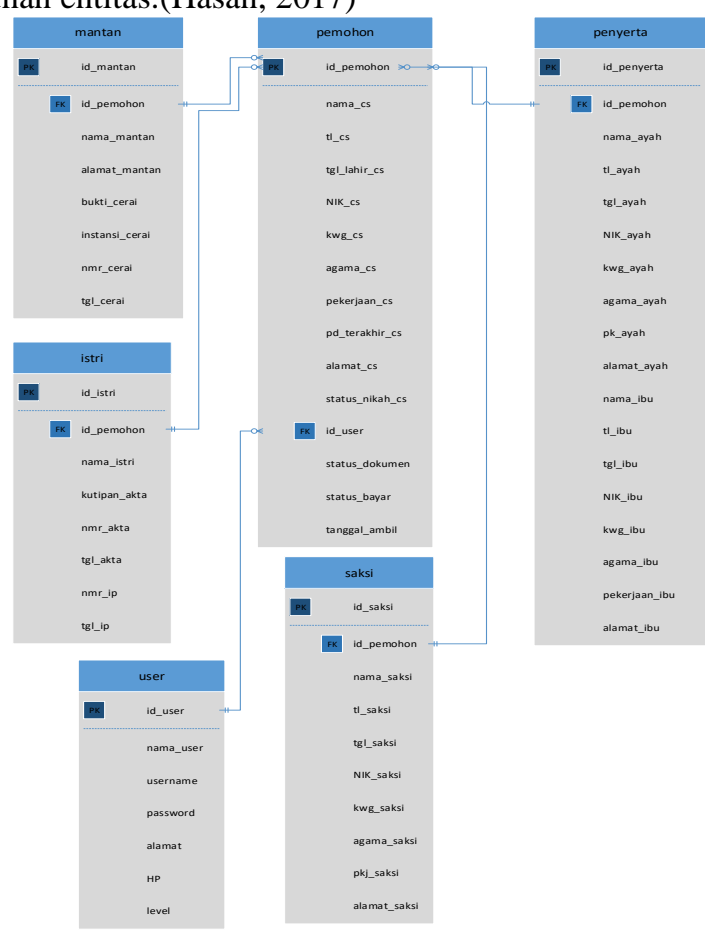

Gambar 2. Logical Record Structure

Struktur Navigasi

Struktur Navigasi Halaman Index (Halaman Utama)
Pada halaman index menggunakan struktur navigasi linier karena beranda, profil KUA, pelayanan, persyaratan dan pendaftaran online serta Login dapat diakses secara urut/berurutan.

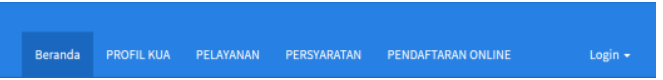

Gambar 3. Struktur Navigasi Halaman Index

Struktur Navigasi Halaman Admin

Pada halaman admin hanya dapat diakses oleh petugas admin, halaman admin menggunakan struktur navigasi linier karena, beranda, informasi, pemohon, pegawai dan logout dapat diakses secara urut/berurutan.

\section{Beranda Informasi Pemohon Pegawai Logout}

Gambar 4. Struktur Navigasi Halaman Admin

Struktur Navigasi Halaman Pemohon

Halaman pemohon dapat diakses oleh user, halaman ini menggunakan struktur navigasi linier karena beranda, isi formulir, upload dokumen persyaratan, form pembayaran dan logout dapat diakses secara urut/berurutan.

\section{Beranda Isi Formulir Upload Dokumen Persyartan Form Pembayaran Logout}

Gambar 5. Struktur Navigasi Halaman Pemohon

Implementasi

Implementasi rancangan antar muka ini adalah hasil penerapan dari aplikasi SIPP berbasis website yang telah dibuat oleh penulis sehingga dapat dilihat nyata dalam bentuk interface.

\section{Pengujian Unit}

Pengujian terhadap program yang dibuat menggunakan blackbox testing yang fokus terhadap proses input dan output program, diantaranya sebagai berikut :

Pengujian terhadap Form Login

Pengujian blackbox testing ini berdasarkan Form Login yang telah dibuat pada website, untuk menguji input dari masing-masing field.

Tabel 1. Hasil Pengujian Blackbox Testing Halaman Form Login

\begin{tabular}{|c|c|c|c|c|c|}
\hline No & Pengujian & $\begin{array}{r}\text { Test case } \\
\end{array}$ & $\begin{array}{l}\begin{array}{l}\text { Hasil } \quad \text { yang } \\
\text { diharapkan }\end{array} \\
\end{array}$ & $\begin{array}{l}\begin{array}{l}\text { Hasil } \\
\text { pengujian }\end{array} \\
\end{array}$ & Kesimpulan \\
\hline & $\begin{array}{l}\text { Username } \\
\text { dan } \\
\text { password } \\
\text { tidak disis } \\
\text { kemudian } \\
\text { klik } \\
\text { tombol } \\
\text { login } \\
\end{array}$ & $\begin{array}{l}\text { Username: (-) } \\
\text { Password:(-) }\end{array}$ & $\begin{array}{l}\text { Sistem } \\
\text { menolak dan } \\
\text { menampilkan } \\
\text { "username } \\
\text { atau pasword } \\
\text { tidak } \\
\text { kosong" boleh } \\
\text { kosong }\end{array}$ & $\begin{array}{l}\text { Sesuai } \\
\text { harapan }\end{array}$ & Valid \\
\hline & $\begin{array}{l}\text { Username } \\
\text { disi dan } \\
\text { password } \\
\text { tidak disi } \\
(-) \\
\text { kemudian } \\
\text { klik } \\
\text { tombol } \\
\text { login }\end{array}$ & $\begin{array}{l}\text { Username: } \\
\text { hmiyelah } \\
\text { Password: (-) }\end{array}$ & $\begin{array}{l}\text { Sistem } \\
\text { menolak dan } \\
\text { menampilkan } \\
\text { "username } \\
\text { atau password } \\
\text { tidak , bleh } \\
\text { kosong" }\end{array}$ & $\begin{array}{l}\text { Sesuai } \\
\text { harapan }\end{array}$ & Valid \\
\hline & $\begin{array}{l}\text { Username } \\
\text { tidak diisi }\end{array}$ & $\begin{array}{l}\text { Username: }(-) \\
\text { Password: } 12346\end{array}$ & $\begin{array}{l}\begin{array}{l}\text { Sistem } \\
\text { menolak dan }\end{array} \\
\end{array}$ & & Valid \\
\hline
\end{tabular}




\begin{tabular}{|c|c|c|c|c|}
\hline $\begin{array}{l}(-) \quad \text { dan } \\
\text { password } \\
\text { disi } \\
\text { kemudian } \\
\text { klik } \\
\text { tombol } \\
\text { login }\end{array}$ & & $\begin{array}{l}\text { menampiikan } \\
\text { "usisername } \\
\text { atau passord } \\
\text { tidak } \\
\text { kosong" }\end{array}$ & $\begin{array}{l}\text { Sesuai } \\
\text { harapan }\end{array}$ & \\
\hline $\begin{array}{l}\text { Mengisi } \\
\text { username } \\
\text { dengan } \\
\text { awalan } \\
\text { huruf } \\
\text { kapital dan } \\
\text { password } \\
\text { kemudian } \\
\text { klik } \\
\text { tombol } \\
\text { login }\end{array}$ & $\begin{array}{l}\text { Username: } \\
\text { Hmiyelah } \\
\text { Password:123456 }\end{array}$ & $\begin{array}{l}\text { System } \\
\text { menerima } \\
\text { Login }\end{array}$ & $\begin{array}{l}\text { Sesuai } \\
\text { harapan }\end{array}$ & Valid \\
\hline 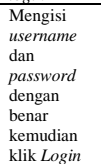 & $\begin{array}{l}\text { Username: } \\
\text { hmiyelah } \\
\text { Password: } 123456\end{array}$ & $\begin{array}{l}\text { Sistem } \\
\text { menerima dan } \\
\text { Login berhasil }\end{array}$ & $\begin{array}{l}\text { Sesuai } \\
\text { harapan }\end{array}$ & Valid \\
\hline
\end{tabular}

Pengujian terhadap Input Data Formulir Pengujian blackbox testing ini berdasarkan Form Input Data Formulir yang telah dibuat pada website, untuk menguji masing-masing field.

Tabel 2. Pengujian Blackbox Testing Input Data Formulir

\begin{tabular}{|l|l|l|l|l|l|}
\hline No & Pengujian & Test case & $\begin{array}{l}\text { Hasil yang } \\
\text { diharapkan }\end{array}$ & $\begin{array}{l}\text { Hasil } \\
\text { pengujian }\end{array}$ & Kesimpulan \\
\hline $\mathbf{1}$ & $\begin{array}{l}\text { Input } \\
\text { formulir } \\
\text { tidak diisi } \\
\text { lalu klik } \\
\text { tombol } \\
\text { Lanjut }\end{array}$ & $\begin{array}{l}\text { Nama (kosong) } \\
\text { TTL(kosong), } \\
\text { NIK(kosong), } \\
\text { agama(kosong), } \\
\text { pekerjaan } \\
\text { (kosong) }\end{array}$ & $\begin{array}{l}\text { Sistem } \\
\text { menyimpan dan } \\
\text { menampilkan } \\
\text { "Data Gagal } \\
\text { Disimpan" }\end{array}$ & $\begin{array}{l}\text { Sesuai } \\
\text { harapan }\end{array}$ & Valid \\
\hline \multirow{2}{*}{$\begin{array}{l}\text { Input } \\
\text { formulir } \\
\text { hanya diisi } \\
\text { sebagian } \\
\text { kemudian } \\
\text { klik Lanjut }\end{array}$} & $\begin{array}{l}\text { Nama (kosong) } \\
\text { TTL(kosong), } \\
\text { NIK(kosong), } \\
\text { agama(ada), } \\
\text { pekerjaan (ada) }\end{array}$ & $\begin{array}{l}\text { Sistem } \\
\text { menyimpan dan } \\
\text { menampilkan } \\
\text { "Data Gagal } \\
\text { Disimpan" }\end{array}$ & $\begin{array}{l}\text { Sesuai } \\
\text { harapan }\end{array}$ & Valid \\
\hline \multirow{3}{3}{} & $\begin{array}{l}\text { Input } \\
\text { formulir diisi } \\
\text { semua } \\
\text { dengan } \\
\text { benar } \\
\text { kemudian } \\
\text { klik Lanjut }\end{array}$ & $\begin{array}{l}\text { Nama (ada) } \\
\text { TTL(ada), } \\
\text { NIK(ada), } \\
\text { agama(ada), } \\
\text { pekerjaan (ada) }\end{array}$ & $\begin{array}{l}\text { Sistem } \\
\text { menyimpan dan } \\
\text { menampilkan } \\
\text { "Data Berhasil } \\
\text { Disimpan" }\end{array}$ & $\begin{array}{l}\text { Sesuai } \\
\text { harapan }\end{array}$ & Valid \\
\end{tabular}

Pengujian terhadap Upload Dokumen Persyaratan Pengujian blackbox testing ini berdasarkan Form Upload Dokumen Persyaratan yang telah dibuat pada website, untuk menguji masing-masing field.

Tabel 3. Pengujian Blackbox Testing Upload Dokumen Persyaratan

\begin{tabular}{|l|l|l|l|l|l|}
\hline No & Pengujian & $\begin{array}{l}\text { Test } \\
\text { case }\end{array}$ & $\begin{array}{l}\text { Hasil yang } \\
\text { diharapkan }\end{array}$ & $\begin{array}{l}\text { Hasil } \\
\text { pengujian }\end{array}$ & Kesimpulan \\
\hline $\mathbf{1}$ & $\begin{array}{l}\text { Ketika input } \\
\text { dokumen } \\
\text { tidak diisi } \\
\text { kemudian } \\
\text { klik tombol } \\
\text { simpan }\end{array}$ & $\begin{array}{l}\text { File: } \\
\text { (kosong) }\end{array}$ & $\begin{array}{l}\text { Sistem tidak } \\
\text { bisa } \\
\text { menyimpan } \\
\text { dan } \\
\text { menampilkan } \\
\text { "File belum } \\
\text { diambil" }\end{array}$ & $\begin{array}{l}\text { Sesuai } \\
\text { harapan }\end{array}$ & Valid \\
\hline $\mathbf{2}$ & $\begin{array}{l}\text { Ketika input } \\
\text { dokumen } \\
\text { hanya diisi } \\
\text { salah satu } \\
\text { lalu klik } \\
\text { tombol } \\
\text { simpan }\end{array}$ & $\begin{array}{l}\text { File: } \\
\text { (kosong) } \\
\text { Choose } \\
\text { File: } \\
\text { (ada) }\end{array}$ & $\begin{array}{l}\text { Sistem tidak } \\
\text { bisa } \\
\text { menyimpan } \\
\text { dan } \\
\text { menampilkan } \\
\text { "File belum } \\
\text { diambil" }\end{array}$ & $\begin{array}{l}\text { Sesuai } \\
\text { harapan }\end{array}$ & Valid \\
\hline
\end{tabular}

\begin{tabular}{|c|c|c|c|c|c|}
\hline 3 & $\begin{array}{l}\text { Ketika input } \\
\text { dokumen } \\
\text { diisi semua } \\
\text { secara } \\
\text { keseluruhan }\end{array}$ & $\begin{array}{l}\text { Choose } \\
\text { File: } \\
\text { (ada) } \\
\text { Choose } \\
\text { File: } \\
\text { (ada) } \\
\text { Choose } \\
\text { File: } \\
\text { (ada) } \\
\text { Choose } \\
\text { File: } \\
\text { (ada) }\end{array}$ & $\begin{array}{l}\text { Sistem } \\
\text { menyimpan } \\
\text { dan } \\
\text { menampilkan } \\
\text { "Data } \\
\text { Berhasil } \\
\text { Disimpan" }\end{array}$ & $\begin{array}{l}\text { Sesuai } \\
\text { harapan }\end{array}$ & Valid \\
\hline
\end{tabular}

\section{KESIMPULAN}

Dari hasil penelitian yang penulis lakukan, maka penulis mengambil beberapa kesimpulan sebagai berikut :

Sebelum adanya aplikasi sistem ini, pendaftaran pernikahan pada KUA masih dilakukan dengan calon pendaftar datang langsung ke kantor urusan agama pada tempat asal mereka masingmasing.

Dengan adanya aplikasi sistem ini lamanya proses pendaftaran pernikahan karena harus mengantri untuk mendaftar atau harus menempuh jarak yang jauh untuk sampai di KUA jadi sedikit teratasi, karena penulis menyadari masih terdapat kekurangan yang harus diterapkan pada aplikasi ini.

Dengan adanya penerapan Aplikasi Sistem Informasi Pelayanan Publik Berbasis Web pada KUA Sungai Raya menggunakan komputer didalam prosesnya, sangat membantu petugas KUA dalam mengelola data-data yang masuk dari calon pendaftar. Pengolahan data-data yang masuk akan mudah di proses dan lebih efisien dengan menggunakan sistem komputerisasi.

Penggunaan Aplikasi Sistem Informasi Pelayanan Publik Berbasis Web pada KUA Sungai Raya ini menggunakan 2 level, yaitu Admin dan Pemohon.

\section{REFERENSI}

Akbar, F., \& Setiaji, S. (2020). RANCANG BANGUN SISTEM INFORMASI KARANG TARUNA MENGGUNAKAN METODE WATERFALL. Jurnal Khatulistiwa Informatika, VIII(1). www.bsi.ac.id

Dwiyanto, A. (2021). Mewujudkan good governance melalui pelayanan publik. UGM PRESS.

Hadi, K., Asworo, L., \& Taqwa, I. (2020). Inovasi Dialogis: Menuju Transformasi Pelayanan Publik Yang Partisipatif (Kajian Sistem Pelayanan Malang Online). Journal of Government and Civil Society, 4(1), 115-129.

Haryani, H., \& Saputra, D. (2021). Designing of Web-Based Learning Media for Senior High School During The Covid-19 Pandemic. International Journal of Educational Research \& Social Sciences, 2(2), 241-254. 
Hasan, H. (2017). IMPLEMENENTASI SISTEM INFORMASI PENGELOLAAN INVENTORY FIXED ASSET PADA PT. ARK LOGISTICS DAN TRANSPORT. Perspektif, 15(2), 155-163.

Ibrahim, H. A. (2019). Teori dan konsep pelayanan publik serta implementasinya.

Ibrahim, W. H., \& Maita, I. (2017). Sistem Informasi Pelayanan Publik Berbasis Web Pada Dinas Pekerjaan Umum Kabupaten Kampar. Jurnal Ilmiah Rekayasa Dan Manajemen Sistem Informasi, 3(2), 17-22.

Martias, M., Azhari, A., \& Saputra, D. (2020). Penerapan Jaringan Virtual Local Area Network Dengan Cisco Packet Tracer. In INSANTEK - Jurnal Inovasi dan Sains Teknik Elektro (Vol. 1, Issue 1). http://ejournal.bsi.ac.id/ejurnal/index.php/insa ntek28

Maulana, R., Rahayuningsih, P. A., Irmayani, W., Saputra, D., \& Jayanti, W. E. (2020). Improved Accuracy of Sentiment Analysis Movie Review Using Support Vector Machine Based Information Gain. Journal of Physics: Conference Series, 1641, 12060. https://doi.org/10.1088/17426596/1641/1/012060

Rahmadana, M. F., Mawati, A. T., Siagian, N., Perangin-angin, M. A., Refelino, J., Tojiri, M. Y., Siagian, V., Nugraha, N. A., Manullang, S. O., \& Silalahi, M. (2020). Pelayanan Publik. Yayasan Kita Menulis.

Rahman, A., Saputra, D., Haryani, H., \& Riswandi, R. (2020). RANCANG BANGUN SISTEM INFORMASI AKUNTANSI PENDAPATAN JASA PADA KLINIK DOKTER ANANDA
DEPOK. Jurnal Khatulistiwa Informatika, $8(2)$.

Saputra, D., Irmayani, W., \& Martias. (2019). PERANCANGAN SISTEM PELAYANAN KESEHATAN (SIYANA) PADA PUSKESMAS MENSIKU DESA BINJAI HULU KABUPATEN SINTANG KALIMANTAN BARAT. Jurnal Mantik PENUSA, 3(1), 37-43. http://www.ejurnal.pelitanusantara.ac.id/index.php/mantik/a rticle/view/656

Saputra, D., Setiaji, S., \& Ishak, R. (2019). PERANCANGAN SISTEM INFORMASI PENGELOLAAN DAN PELAYANAN PERPUSTAKAAN BERBASIS WEB (STUDI KASUS MAN I KOTA TANGERANG SELATAN). Jurnal Mantik Penusa, 3(1), 33$42 . \quad$ http://www.ejurnal.pelitanusantara.ac.id/index.php/mantik/a rticle/view/542

Sinambela, L. P. (2019). Reformasi pelayanan publik: teori, Kebijakan dan implementasi.

Wijaya, E. S. (2020). APLIKASI PENYEWAAN RUANGAN BESERTA FASILITAS BERBASIS WEB PADA SUDIRMAN CITY CENTER OFFICE TOWER BESTON HOTEL PALEMBANG. POLITEKNIK NEGERI SRIWIJAYA.

Yulia, E. R., \& Nuris, N. (2018). Perancangan sistem informasi penjualan obat pada klinik ibu mas depok. JUSIM (Jurnal Sistem Informasi Musirawas), 3(02), 116-125. 